\title{
建筑电气施工因素及问题探讨
}

\author{
章建文 蔡旭光 \\ 浙江中煌建设有限公司
}

DOI:10.32629/btr.v3i3.2927

[摘 要] 随着智能化建筑的不断兴起,对电气施工技术也提出了更高的要求, 因此, 建筑电气施工必须从“线路”、“防雷”、“材料”这三个方面 进行考虑。现就建筑电气工程施工工作谈一些体会。

[关键词]建筑电气; 施工; 建设

\section{1 影响建筑电气施工的因素}

1. 1 建筑电气施工现场的线路安全。不安全的管线表示有发生火灾的 可能性。如果发生火灾, 会对施工质量产生巨大影响。因此, 在用电时必须 非常小心。电路不安全的原因是电路短路。首先, 要遇到短路, 相线短路以 及安装过程中出现的问题。如果断路器接线电阻增加, 则很容易发生相间 短路。其次, 在安装电线的过程中, 不允许执行裸线太低或线间距太小的操 作。如果间距太小, 则更可能发生线对线碰撞。当安装断路器时, 不能保证 空间的干燥, 这将导致水蒸气击穿短路。

1.2防雷问题。严格监督检查电气结构的防雷装置。首先, 许多避雷针 的弯曲半径是不一样的, 对于设计要求, 许多避雷针的角的弯曲半径根本 不能满足要求。专业人士需要检查安装。间距不够均匀, 在安装从屋顶突 出的金属物体时, 防雷装置可能无法牢固连接。另外, 引下线和防雷区的横 截面的质量较差并且小于防雷区的横截面。最后, 接地电极电阻测试点的 设置与相关要求不一致, 并且防雷接地装置测试点的金属物体的防腐措施 不到位。

1. 3材料质量问题。在施工过程中, 一些制造商降低了产品质量以获取 更多利益。结果, 电气结构的质量受到威胁, 发生不安全的事故, 甚至造成 巨大的经济损失。建筑电气建筑材料的质量问题包括导线电阻率高, 机械 性能差, 熔点低, 温度系数大和绝缘性差; 耐腐蚀性差, 电缆耐压低, 耐低温 并且开关插座的导电值不符合标称值, 使导电金属的弹性不强, 不能满足 安全性要求等。在特定的施工过程中, 经常使用假冒产品。许多配电箱中 空气断路器和漏电开关的型号或额定电流值与设计不匹配, 并且这些开关 要小得多。

\section{2 电气工程管线施工}

2. 1 电气工程管道铺设。(1) 根据图纸要求或其他具体要求, 施工人 员必须熟悉管道的设计, 包括管道的规格,敷设方法, 具体型号等。(2) 在 施工过程中, 必须严格按照工程设计图连接和铺设管道。同时, 必须严格 执行相关设计, 例如保护层和管道开口。应及时进行检查以互相监督, 以 确保施工质量。(3) 天花板和地板的管道铺设, 地板和墙壁的管道铺设应 根据不同的要求进行处理, 防止管道被水泥等堵塞, 并注意管道的损坏 和形变。

2. 2 关于管道和金属线槽内的布线。后土木结构施工完成后, 首先应清 理管道和线槽, 并同时处理相应的边缘保护层。在穿线过程中, 请注意特定 的三色线。电线接头不得出现在导管中, 并且应执行相应的电阻绝缘测试。 根据不同的测试标准确定是否合格。

2.3 电缆敷设。(1) 通过检查的电缆可以安装在电气设备, 配电箱, 配电 柜等中, 并可以在测试后敷设。(2) 根据拉出的电缆, 排列图表, 选择合适的
电缆进行铺设和测试。在电缆敷设过程中, 应暂停电缆的特定特性, 例如型 号, 电压等级或其他数字。敷设电缆时, 应根据具体要求合理科学地敷设电 缆。(3) 如果遇到其他特殊情况, 应作技术说明并做好相应记录。

\section{3 地面干线建设}

3. 1地面行李箱支架的安装。安装接地干线时, 应根据施工结构的要求, 尽量埋入相应的支撑结构或铁件。应根据相应的设计要求对其进行划分和 定位。气创时, 开口的尺寸应相同。

3. 2 敷设扁管以防雷和防雷。铺设前应将所需的扁钢拉直。矫直的扁 钢用作引下线, 可运输到每个特定的安装地点。根据特定的设计要求在建 筑物上进行处理。之后, 将下端焊接到接地体, 也可以将其连接到断开卡。 随着建筑物的逐渐增加, 引下线将被铺设在建筑物的屋顶上, 并从屋顶伸 出一定长度, 以准备与雷电保护网络连接。如果需要接头, 则应焊接。焊接 后, 应将皮肤弄掉并用防锈漆刷净。最后, 相关的施工人员将接受并记录相 应的记录。

3. 3 避雷网和避雷针的安装操作。在安装之前, 必须拉直防雷网和避雷 针。根据相应的操作步骤, 将防雷网和避雷针焊接到相应的位置。完成后, 进行表面处理, 并施加银粉和防锈漆。

\section{4 建筑防雷施工}

4. 1接地体的安装。在建筑设计中, 我们经常使用桩基和平台钢筋作为 建筑接地体。焊接桩基钢筋与主钢筋对应的数量和位置, 并进行相应的防 腐防锈处理, 并作标记, 以备将来检查。

4. 2 接地体按规定完成后, 应进行相应的验证。验证时, 其位置, 材料和 焊接工艺应满足设计, 施工和防雷验收规范的特定要求, 方可填埋。

4. 3 接地体在安装过程中有严格的规定。在加工过程中, 应按规定严格 设计安装, 配置和防腐处理。同时, 接地体与建筑物之间的距离也有具体规 定。例如, 除环形接地体外, 接地体应埋在距离建筑物 3 米以上的地方。

4. 4 在安装之前, 必须先侧向调整接地干线, 然后再安装。铺设时, 首先 根据相应的设计要求挖出相应尺寸的沟槽, 并将扁钢侧向放入。压实和回 填。为了方便接地线的连接, 请注意接地主线从地面露出的部分应小于 50 厘米。

\section{[参考文献]}

[1]黄国斌.建筑电气施工安装技术及质量管控方式研究[J].建材与装 饰,2019(19):2-3.

[2]陈春娟.建筑电气安装施工及质量控制研究 [J].科技创新与应 用,2019(19):139-140

[3] 郭浩.建筑电气安装施工技术及质量管理 [J].住宅与房地 产,2019(09):124. 